\title{
Polycystic liver disease: an overview of pathogenesis, clinical manifestations and management
}

\author{
Wybrich R Cnossen and Joost PH Drenth
}

\begin{abstract}
Polycystic liver disease (PLD) is the result of embryonic ductal plate malformation of the intrahepatic biliary tree. The phenotype consists of numerous cysts spread throughout the liver parenchyma. Cystic bile duct malformations originating from the peripheral biliary tree are called Von Meyenburg complexes (VMC). In these patients embryonic remnants develop into small hepatic cysts and usually remain silent during life. Symptomatic PLD occurs mainly in the context of isolated polycystic liver disease (PCLD) and autosomal dominant polycystic kidney disease (ADPKD). In advanced stages, PCLD and ADPKD patients have massively enlarged livers which cause a spectrum of clinical features and complications. Major complaints include abdominal pain, abdominal distension and atypical symptoms because of voluminous cysts resulting in compression of adjacent tissue or failure of the affected organ. Renal failure due to polycystic kidneys and non-renal extra-hepatic features are common in ADPKD in contrast to VMC and PCLD. In general, liver function remains prolonged preserved in PLD. Ultrasonography is the first instrument to assess liver phenotype. Indeed, PCLD and ADPKD diagnostic criteria rely on detection of hepatorenal cystogenesis, and secondly a positive family history compatible with an autosomal dominant inheritance pattern. Ambiguous imaging or screening may be assisted by genetic counseling and molecular diagnostics. Screening mutations of the genes causing PCLD (PRKCSH and SEC63) or ADPKD (PKD1 and PKD2) confirm the clinical diagnosis. Genetic studies showed that accumulation of somatic hits in cyst epithelium determine the rate-limiting step for cyst formation. Management of adult PLD is based on liver phenotype, severity of clinical features and quality of life. Conservative treatment is recommended for the majority of PLD patients. The primary aim is to halt cyst growth to allow abdominal decompression and ameliorate symptoms. Invasive procedures are required in a selective patient group with advanced PCLD, ADPKD or liver failure. Pharmacological therapy by somatostatin analogues lead to beneficial outcome of PLD in terms of symptom relief and liver volume reduction.
\end{abstract}

Keywords: Cystogenesis, Polycystic liver disease (PLD), Hepatomegaly, Biliary tract disease, Ductal plate malformation (DPM), Von Meyenburg complex (VMC), Autosomal dominant polycystic liver disease (PCLD), Autosomal dominant polycystic kidney disease (ADPKD)

\section{Review}

\section{Disease name}

Polycystic liver disease (PLD) is a collection of rare human disorders that result from structural changes in the biliary tree development [1,2]. Genetic mechanisms and/ or signaling defects are the root cause of ductal structures to become separated from the biliary tree finally

\footnotetext{
* Correspondence: joostphdrenth@cs.com

Department of Gastroenterology and Hepatology, Institute for Genetic and Metabolic Disease, Radboud university medical center, Geert Grooteplein-Zuid 10, P.O. Box 9101, 6525 GA Nijmegen, The Netherlands
}

resulting in cyst formation [2,3]. Typically, these disconnected biliary structures are present in a very early disease stage, but remain asymptomatic until cyst growth initiates in adulthood [4].

Three PLD entities are recognized in adults. Von Meyenburg complexes (VMC; biliary hamartoma; hepatic cystic hamartoma) with characteristic small, nonhereditary nodular cystic lesions [ORPHA386] [4,5]. Isolated polycystic liver disease (PCLD; autosomal dominant PLD) [OMIM\#174050; ORPHA2924] with presence of innumerable hepatic cysts and autosomal dominant 
polycystic kidney disease (ADPKD) [OMIM\#173900; OMIM\#613095; OMIM\#600666; ORPHA730] with cysts in both kidneys and in many cases hepatic cysts.

This paper reviews the pathological and clinical features of these 3 adult cystic disorders that share presence of numerous hepatic cysts with an intact biliary tree architecture.

\section{Definition}

PLD is a rare inherited Mendelian disorder that is characterized by development of multiple hepatic cysts. The classification of PLD follows the histological changes that are due to ductal plate malformation (DPM) during fetal development [6,7]. Definitions of cystic malformations are either based on the location of the affected (cilium-related) protein or follows radiological findings $[8,9]$.

\section{Ductal plate malformation}

The biliary tree emerges from the endodermal hepatic diverticulum [1]. Development of the biliary system starts from the $8^{\text {th }}$ week of gestation by formation of single layered hepatoblasts surrounding the portal vein (ductal plate). Duplication of ductal plate cells forms a double layer that finally dilate to a tubular structure, the primitive bile duct. Hepatoblast differentiation to a biliary phenotype and tubulogenesis is stimulated by the Notch, TGF- $\beta$ and canonical Wnt signaling pathways [2]. Cell differentiation from hepatoblasts to cholangiocytes, tubule elongation and bile duct remodeling are completed by 30 weeks of gestation. Intrahepatic and extrahepatic bile duct systems are then merged and share the hepatic hilum. During the first year of life intrahepatic biliary epithelium maturates further [1,2,7]. PLD develops as a result of ductal plate malformation. The stage that is affected by faulty remodeling determines the phenotype. For example, VMC is thought to result from embryonic ductal involution at a late stage $[7,10]$.

Bile duct formation requires a network of epithelialmesenchymal interactions, and presence of growth and transcription factors to control appropriate cell migration, adhesion and cholangiocyte differentiation. Aberrant expression profiles and signaling result in deficient remodeling, and subsequently abnormal dilated or disconnected ductal plate cells developing into biliary cystic structures $[3,11]$. Recently, a new classification for DPM has been proposed on the basis of Hnf-1ß, Hnf- 6 and cystin-1 gene deficient mouse models. This classification distinguishes 3 DPMs: 1) abnormal hepatoblast differentiation, 2) failure of bile duct maturation, 3) perturbation of ductal expansion [6].

\section{Ciliopathy and cholangiopathy}

Ciliopathies represent an emerging class of human disorders that are caused by defects in distinct genes affecting ciliary structures or function. They may be inherited as simple recessive traits, but also in a dominant fashion. Phenotypic expressivity is under the control of numerous genetic modifiers [8]. Ciliopathies usually result in shared clinical features, such as intellectual disability, retinal defects and polydactyly, but the most well-known phenotype is that of cystic kidneys [12]. The proteins affected in ADPKD are located at the cilium which has led to the classification of ADPKD as a ciliopathy [13]. By contrast, the proteins associated with PCLD are not located to the cilium. Hepatic cysts are lined by cholangiocytes and therefore the term cholangiopathy is used for PCLD [3].

\section{Radiology}

Radiological imaging assists in classifying PLD. Detection of macroscopically hepatic and renal cysts is facilitated by ultrasonography, magnetic resonance imaging (MRI) or computed tomography (CT)-scanning without or with (creatinine-permitting) intravenous contrast material [9]. On ultrasound, cysts appear as homogeneous anechoic fluid-filled round spaces. MRI is superior over ultrasound and CT, and allows better detection of small cysts in young individuals [14]. This technique captures biliary tree pathology and differentiates parenchym from biliary tree (Figure 1).

\section{Epidemiology}

PCLD has a prevalence of $1 / 100,000$ to $1 / 1,000,000$ or 1- $9 / 100,000$ (1/158,000 in The Netherlands), while the prevalence of ADPKD ranges between $1 / 400$ to $1 / 1,000$ $[13,15]$. The incidence of VMC has been estimated up to $1 / 18-1 / 145$ or $7-60 / 1,000(0.69-5.6 \%)$ depending on the various autopsy studies $[10,16]$.

\section{Clinical description \\ Von Meyenburg complexes}

$\mathrm{VMC}$, also termed microhamartomas, are benign cystic nodules scattered throughout the liver. They are usually interlobularly located and at peripheral bile ducts below the Glisson's capsule [7]. VMC may occur isolated or in the context of PCLD and ADPKD $[4,11,17]$. VMC are frequently an incidental finding at radiological imaging, surgery or autopsy studies.

Histologically, they are characterized by small embryonic DPM remnants $(<1.5-\mathrm{cm}$-diameter) or larger (small) hamartomas $(>1.5 \mathrm{~cm})$ delineated by regular cuboidal epithelium and embedded in fibrous stroma. Dilated structures initially communicate with the peripheral intrahepatic biliary tree, but separate with development $[7,10]$.

VMC usually remain silent during life and require no management or follow-up examination [17]. Although mild liver test disturbances may be observed, significant hepatomegaly or liver disease is rare in VMC. Incidentally, clinical features of epigastric pain, fever, cholangitis and jaundice 


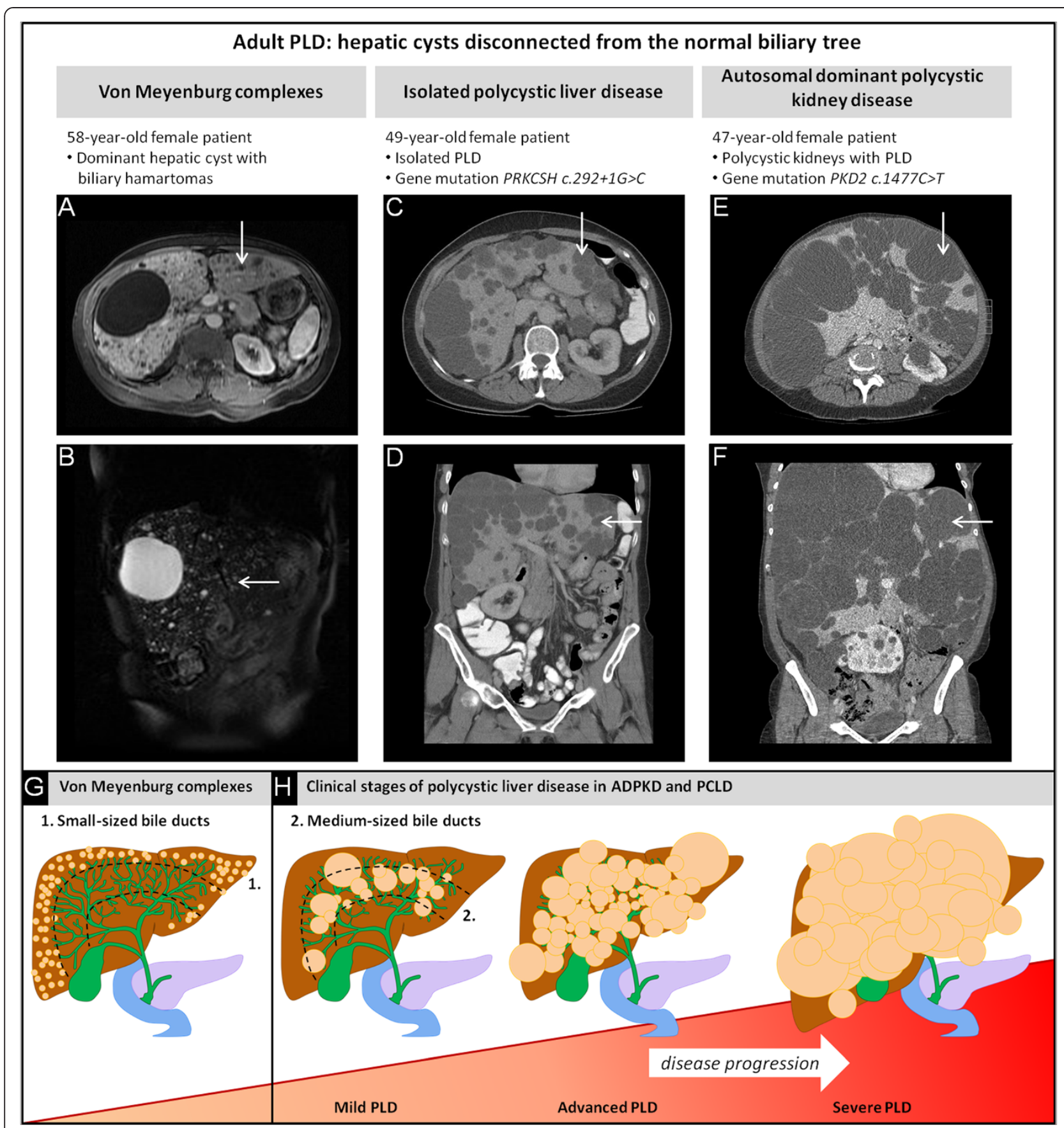

Figure 1 Abdominal MRI and CT in patients with PLD. (A) Axial T1-weighted and (B) coronal T2-weighted MRI present 1 large cyst and numerous cystic nodules scattered at peripheral bile ducts. (C-D) CT-scanning in a PCLD patient presents multiple cysts originating from medium-sized bile ducts. (E-F) Co-occurrence of polycystic kidneys exists in ADPKD. Both PRKCSH and PKD2 gene mutations were predicted to be pathogenic (GRCh37-hg19; HGMD). Hepatic cysts are indicated by white arrows. (G) Diffuse VMC present numerous small-sized hepatic cysts located at peripheral branches of the biliary tree (in green). (H) The PLD phenotypes are arbitrarily staged and indicate disease progression. The disease course is progressive in a subset of severely affected PLD patients.

appear when communication of multicystic VMC with the biliary tree cause biliary obstruction [18]. Episodes of liver sepsis indicates antibiotic treatment and follow-up of liver function tests. Abdominal pain and discomfort resolves with time. The diagnosis of VMC can be confirmed by MRI. Extra-hepatic features are absent.

\section{PCLD and ADPKD}

Hepatic cysts are the major clinical feature in PCLD and the most frequent extra-renal manifestation in ADPKD [14]. Cysts originate from medium-sized bile ducts. Histologically, they are delineated by cuboidal, flattened epithelial cells surrounded by fibrous stroma [7]. 
They may be confined to 1 or more segments or spread evenly throughout the liver. Presence of large and numerous cysts frequently lead to hepatomegaly. One study showed that the overall hepatic cyst prevalence in ADPKD patients (age range15-46 years) is $83 \%$, with the highest prevalence of $94 \%$ in 35- to 46-year-old patients. This corresponds with an increased prevalence of multiple hepatic cysts in older PLD patients [14].

The variable number, size, location and distribution of cysts determines the spectrum of symptoms which is related to the extent of hepatomegaly [4]. Pain may ensue mainly because of tension on Glisson's liver capsule. Abdominal discomfort, pyrosis, early satiety, weight loss and anorexia may arise in advanced PLD [15,19]. Patients who have large hepatic cysts that exert pressure on the stomach and displacement of other abdominal organs are at risk for malnutrition and nutritional deficiencies [20].

Females with ADPKD or PCLD usually have a more severe liver phenotype, especially for those with a history of multiple pregnancies and prolonged exogenous estrogen exposure [17,21,22]. Females have higher average liver volumes, are younger at presentation and more susceptible to progressive PLD, suggesting a hormonal component $[14,15,19]$. In general, patients with PCLD have more severe symptoms and liver-related complications compared to ADPKD [23]. Hepatic cysts are rarely present in young children, but in exceptional cases symptomatic PLD may develop in young ADPKD patients.

The risk to develop severe PLD is independent from the ADPKD genotype, but is related to the severity of renal disease $[13,23]$. Here, presence of a PKD1 mutation puts the patient at risk for an earlier onset and outcome of renal disease compared to the PKD2 [24,25].

\section{Hepatic complications in PCLD and ADKPD}

Complications may occur due to massively hepatomegaly or result from invasive treatment $[15,19]$. It has been estimated that about half of the patients with advanced hepatic disease have had cyst hemorrhage, cyst rupture or a cyst infection $[15,26]$. These manifestations appear to be more frequent in ADPKD compared to PCLD [27]. Here, we will discuss the clinical and diagnostic signs for cyst hemorrhage, rupture, infection and other rare complications in PCLD and ADPKD.

\section{Hemorrhage}

Intrahepatic cyst bleeding typically presents as acute pain in the upper right-side of the abdomen. Symptoms develop acutely, progress in the first day(s), but resolve spontaneously. Sometimes, the nature of the abdominal pain can be colicky and accompanied by vomiting. Ultrasonography may be helpful to assess features suggestive for cyst bleeding such a higher attenuation value, aggregated fibrin deposits and possibly internal septa of hematomas. High signal intensity on MRI supports the diagnosis of an intrahepatic cyst bleeding $[9,28]$.

\section{Infection}

Cyst infections are a serious complication because of its indolent course, demanding treatment and high risk of recurrence. Current diagnostic criteria rely on clinical, biological and radiological parameters including abdominal tenderness, fever $\left(>38^{\circ} \mathrm{C}\right.$ for $>3$ days), an increased $\mathrm{C}$-reactive protein level and proven absence of spontaneous intra-cystic bleeding by CT-scanning. Hepatic cyst wall thickening and heterogeneous fluid (debris) are suggestive for infection. The diagnostic accuracy of MRI is unknown and CT-scanning has a low sensitivity and specificity to identify cyst infection [29]. ${ }^{18}$ F-FDG positron emission tomography (PET)-imaging technique is preferable to detect the exact location of the infected lesion(s) [29].

PLD patients may have strongly elevated CA19-9 levels [30]. Extremely high CA19-9 levels were found in episodes with hepatic cyst infection and declining during recovery [31]. Detection of neutrophils and infectious agent(s) in the cyst fluid aspirate confirms the cyst infection and indicative for targeted antibiotic treatment [29].

\section{Rupture}

Cyst rupture is an exceptional rare complication and presents with acute onset of pain. Hemodynamic complications are rare, but have been reported in the literature [32]. Abdominal discomfort from prolonged ascites and increased cyst volume needs stringent follow-up. If intra-peritoneal (blood) fluid leakage persists, a surgical intervention is inevitable for hemostasis control [28].

\section{Portal hypertension and ascites}

In advanced stages there are 2 processes that may lead up to portal hypertension. First, there is reduction of hepatic vein outflow. Secondly, portal vein inflow may be compressed in advanced disease due to the volume effect of cysts.

Signs of hepatic vein outflow obstruction (HVOO) are abdominal pain, hepatomegaly and transudative ascites (90-96\%) [33]. Hepatic vein thrombosis is commonly recognized as the cause of $\mathrm{HVOO}$, and case series reported also the Budd-Chiari syndrome secondary to PLD [33,34]. The survival of hepatic vein thrombosis is low in severe cases [35]. Mechanical pressure symptoms of hepatomegaly may extend from hepatic veins to junctions with the vena cava inferior (IVC). Compression of IVC is characterized by increased renal outflow pressure that provokes development of ascites and edema in the lower extremities [36]. 
In addition, hepatic cysts may cause a compromised portal venous flow [37]. These abovementioned complications lead to development liver fibrosis. Secondary complications of portal hypertension are the result of severe liver fibrosis such as esophageal varices, splenomegaly and transudative ascites may develop, but advanced fibrosis is a rare event [26]. Typically these features are seen in the elderly. In addition, lymphatic leak and chronic renal disease may contribute to development of ascites in severe PLD patients [33,37].

\section{Jaundice}

Portal hypertension may be accompanied by other signs of hepatic failure such as jaundice [38]. Although jaundice is usually seen in advanced stages, it may occur at any stage. An uncommon cause of jaundice is obstruction of the intrahepatic or extrahepatic bile ducts by hepatic cysts [26]. Recurrent cholangitis is a rare complication of this condition [34].

\section{End-stage liver disease}

Progression to end-stage liver disease usually results in the context of extremely increased liver volumes. Liver failure is seen incidentally, usually in a very late stage of the disease $[15,19]$. Symptomatic patients with hepatomegaly (severe PLD) frequently do not meet the Model for End-Stage Liver Disease (MELD). Therefore, MELD exception criteria including assessment of malnutrition and quality of life are used [20]. Liver transplantation has excellent survival rates $(>90 \%$ at 5 year) $[39,40]$.

\section{Extra-hepatic manifestations \\ Kidney}

The main differentiating feature between PCLD and ADPKD is the presence of polycystic kidneys. While this is the primary lesion in ADPKD, renal disease is absent in PCLD [27]. Disease progression depends on genotype, but also on environmental factors [25]. The majority of adult ADPKD patients develop enlarged kidneys and end-stage renal disease. In contrast, few renal cysts may be present in 28-35\% of PCLD patients, but renal failure does not occur $[15,19]$.

In contrast to PCLD, ADPKD is a multi-systemic disorder. Hypertension is one of the first signs of renal disease development and is related to progressive kidney enlargement and loss of renal function [41,42]. It is still unclear whether early anti-hypertensive treatment prevents renal function decline [43]. The most common feature is abdominal/flank pain due to pressure symptoms and stretching of the renal cyst wall. ADPKD patients are also at-risk for other renal complications such as hematuria, urinary tract infections and kidney stones [21,41].

\section{Cardiovascular system}

ADPKD patients may develop hypertension, intracranial aneurysms (ICA), arterial aneurysms and several cardiac valvular abnormalities [44]. Early assessment of cardiovascular risk factors in ADPKD is advised, especially in young ADPKD patients $[45,46]$.

Mitral valve prolapse has a higher prevalence in ADPKD up to $25-41.2 \%$ compared to $0-10.5 \%$ in PCLD $[19,27,47,48]$. Other important connective tissue abnormalities such as aortic root dilatation and abdominal aorta aneurysm (AAA) have been reported in ADPKD [49]. If the family history is positive, screening of unaffected family members by MR-angiography is recommended [50,51].

\section{Non-renal extra-hepatic cysts}

The phenotype of PCLD is mainly restricted to the liver. Extensive radiological imaging of ADPKD patients have demonstrated that there are cysts in other abdominal organs such as the pancreas (9\%) or seminal vesicles of the testis $(43 \%)$ [52,53]. These cystic manifestations symptomatically silent.

Arachnoid cysts is central nervous system manifestation that is seen in $8 \%$ of ADPKD patients. This condition may occasionally lead to a subdural hematoma [50].

\section{Abdomen}

Abdominal wall hernias may be present in PLD patients. Clinical series have suggested that (para)umbilical and inguinal hernias may be seen in up to $15-45 \%$ of ADPKD patients which may be explained by chronic compression due to high liver and kidney volumes [27,41,54]. Early reports have suggested a higher prevalence of colonic diverticuli in PLD, but upon scrutiny there was no evident association or increased risk for diverticular disease $[27,55]$.

\section{Etiology}

\section{Germline mutation}

Genetic analyses of both PCLD genes PRKCSH [OMIM*177060] and SEC63 [OMIM*608648] may confirm the clinical diagnosis and differentiate it from other PLD (Table 1) [56-58]. These genes encode for the (glyco)proteins hepatocystin and Sec63p [59]. Both proteins are located within the endoplasmic reticulum (ER) and are responsible for quality control and translocation of glycoproteins into the ER [60]. Since about 16-22\% of PCLD patients harbor a pathogenic variant, PCLD is assumed to be genetically heterogeneous and other loci should be nvolved. There is no clear genotype-phenotype association $[15,61]$.

Mutations in the PKD1 gene [OMIM*601313] or PKD2 gene [OMIM*173910] are responsible for renal cyst initiation in $>90 \%$ of the cases [62]. Several ADPKD families possess no mutations on PKD1 or 
Table 1 Genetic and diagnostic determinants of PCLD and ADPKD

\begin{tabular}{|c|c|c|c|}
\hline & Polycystic liver disease(PCLD) & $\begin{array}{l}\text { Autosomal dominant polycystic } \\
\text { kidney disease (ADPKD) }\end{array}$ & Reference \\
\hline \multicolumn{4}{|l|}{ Genotype } \\
\hline \multirow{2}{*}{$\begin{array}{l}\text { Cytogenetic gene location } \\
\text { (mutation frequency\%) }\end{array}$} & Chr.19p13.2: PRKCSH (15\%) & Chr.16p13.3: PKD1 (75.7\%) & \multirow[t]{2}{*}[62,63]{} \\
\hline & Chr.6q21: SEC63 (5.7\%) & Chr.4q21: PKD2 (13.4\%) & \\
\hline Mutation (type; N,\%) & 25 PRKCSH 22 SEC63 & 980 PKD1 193 PKD2 & \multirow[t]{7}{*}{ [HGMD] } \\
\hline missense & $4(16 \%) 6(27.3 \%)$ & $250(25 \%) 29(15 \%)$ & \\
\hline splice site & $4(16 \%) 3(13.6 \%)$ & $77(7.8 \%) 32(16.6 \%)$ & \\
\hline insertion/deletion & $10(40 \%) 7(31.8 \%)$ & $440(45 \%) 80(41.5 \%)$ & \\
\hline indel & $1(4 \%)-$ & $13(1.4 \%) 7(3.6 \%)$ & \\
\hline nonsense & $6(24 \%) 6(27.3 \%)$ & $202(20 \%) 45$ (23.3\%) & \\
\hline complex rearrangement & - & $8(0.8 \%)-$ & \\
\hline \multirow[t]{4}{*}{ Gene product; protein localization } & Cholangiopathy & Ciliopathy & \multirow[t]{4}{*}[13,60]{} \\
\hline & $\begin{array}{l}\text { Hepatocystin/ glucosidase II- } \beta \\
\text { subunit; ER }\end{array}$ & $\begin{array}{l}\text { Polycystin-1 (TRPP1); primary cilium, } \\
\text { tight junction, extracellular matrix, ER }\end{array}$ & \\
\hline & $\begin{array}{l}\text { Translocation protein SEC63 } \\
\text { homolog; }\end{array}$ & $\begin{array}{l}\text { Polycystin-2 (TRPP2); primary cilium, } \\
\text { tight junction, extracellular matrix, ER }\end{array}$ & \\
\hline & ER, membrane complex & & \\
\hline \multirow[t]{2}{*}{ Protein function } & $\begin{array}{l}\text { Proper protein folding and protein } \\
\text { quality control }\end{array}$ & $\begin{array}{l}\text { PC-1 and } P C-2 \text { form a mechanosensor } \\
\text { complex on the primary cilium }\end{array}$ & \multirow[t]{2}{*}[13,60]{} \\
\hline & Posttranslational protein transport & $\begin{array}{l}\text { PC-1 for signaling detection, } P C-2 \text { is a } \\
\text { TRP channel for calcium influx }\end{array}$ & \\
\hline \multicolumn{4}{|l|}{ Predominant phenotype } \\
\hline Liver features & \multirow[t]{2}{*}{ Positive family history with: } & \multirow{5}{*}{$\begin{array}{l}\text { Most common extra-renal manifestation: 83\% } \\
\text { with a polycystic liver ( }>20 \text { hepatic cysts) }\end{array}$} & \multirow[t]{5}{*}[14,64]{} \\
\hline PCLD diagnostic criteria: & & & \\
\hline \multirow[t]{3}{*}{ Clinical practice: } & \multirow{3}{*}{$\begin{array}{l}<40 \text { years and } \geq 1 \text { hepatic cyst } \\
\geq 40 \text { years and } \geq 4 \text { hepatic cysts } \\
30-70 \text { years and polycystic liver } \\
\text { ( }>20 \text { hepatic cysts) }\end{array}$} & & \\
\hline & & & \\
\hline & & & \\
\hline \multirow{8}{*}{$\begin{array}{l}\text { Kidney features } \\
\text { ADPKD diagnostic criteria: }\end{array}$} & \multirow{8}{*}{$\begin{array}{l}\text { Incidental finding without renal } \\
\text { disease: } 28-35 \% \text { with renal } \\
\text { cystogenesis }\end{array}$} & $\begin{array}{l}\text { Positive family history with unknown } \\
\text { genotype: }\end{array}$ & \multirow[t]{8}{*}{$15,19,65,66$} \\
\hline & & $15-39$ years and 3 renal cysts ${ }^{\#}$ & \\
\hline & & $40-59$ years and 2 renal cysts* & \\
\hline & & $\geq 60$ years and 4 renal cysts* & \\
\hline & & Negative family history: & \\
\hline & & $<30$ years and 5 renal cysts ${ }^{\$}$ & \\
\hline & & $30-60$ years and 5 renal cysts ${ }^{5}$ & \\
\hline & & $>60$ years and 8 renal cysts ${ }^{5}$ & \\
\hline
\end{tabular}

Description of the data: A detailed overview of genotype characteristics and diagnostic criteria for PCLD and ADPKD phenotype assessment.

\# unilateral or bilateral.

* in each kidney.

$\$$ bilateral.

PKD2 $[67,68]$. It is hypothesized that these cases are linked to another (yet unidentified) PKD3 gene [OMIM*600666] [69]. PKD1 gene carriers have a higher prevalence of hypertension, complications and a higher risk of progressive renal failure compared to $P K D 2$. Renal failure occurs at a much earlier age in PKD1 carriers compared to PKD2 carriers [41].

\section{Second-hit hypothesis}

PLD patients have a heterozygous germline mutation and it is hypothesized that cysts arise through functional loss of the second allele [59]. This is the rate-limiting step in the formation of cysts. Secondary, somatic hit mutations have been identified in PKD1 or PKD2 genes in liver and kidney tissues from ADPKD patients [70,71]. Similarly, 
loss-of-heterozygosity of the PRKCSH or SEC63 allele is present in PCLD cyst tissues. This is fitting with the second-hit-model for tumorgenesis which dictates that the combination of a germline and somatic mutations result in inactivated protein in target tissues [72,73].

\section{Modifier genes and environmental factors}

Mouse models suggest that additional genes may lead to hepatic and renal cystogenesis [6]. It has been shown that $H N F-1 \beta$ mutations affect disease progression and outcome in ADPKD [25,74].

Once a cyst have been formed, progression to clinical significant disease requires other mechanisms [8]. Cyst fluid contains serum proteins but also cytokines and growth factors which contribute to cyst formation [75,76]. Expression of estrogen hormone receptors in cyst epithelium may trigger growth advantages [77].

\section{Diagnosis}

VMC is a radiological diagnosis $[9,10]$. Ultrasonography shows multiple hyperechoic areas in the subcapsular region. The comet-tail sign is a special form of reverberation artifact in detection of small cysts. This sign appears as a trail on the image if small calcific or highly reflective foci are interrogated on ultrasound [5]. MRI is preferred above CT-scanning as it readily shows multiple hyperintense focal lesions on T2-imaging [9].

Current diagnostic criteria in PCLD and ADPKD rely on the age-related cystic liver phenotype with a positive family history of autosomal dominant inheritance (Figure 2)
[64-66]. Ultrasonography of the liver and kidneys is usually the first modality used to assess a cystic phenotype. The unified Ravine criteria for diagnosis of ADPKD relies on counting the number of renal cysts in at-risk individuals $[65,66]$.

A single laboratory test that is of discriminative value for PLD is lacking. The synthetic liver function is usually preserved in PLD. Mild elevations of $\gamma$-glutamyltransferase sometimes combined with elevated alkaline phosphatase values may be detected $[15,19]$.

\section{Differential diagnosis}

PLD is a non-communicating biliary tree disorder and should be differentiated from other neoplastic, infectious and traumatic conditions [4]. The diffusion and variable small-sized hyperechoic structures in VMC are important to differentiate from hepatic metastasis or microabcesses [9].

In general, differentiation from communicating biliary tree disorders is important for management and prognosis. Bile duct ectasias or cystic dilatations belong to connected intrahepatic cystic diseases. These features are detected in ARPKD, Caroli disease (CD) and Caroli syndrome (CS). PLD is characterized by intrahepatic disease, a more late onset of disease in adulthood and absence of congenital hepatic fibrosis (CHF).

\section{Autosomal recessive polycystic kidney disease}

Young and adult ADPKD patients are difficult to distinguish with other hepatorenal fibrocystic diseases such as

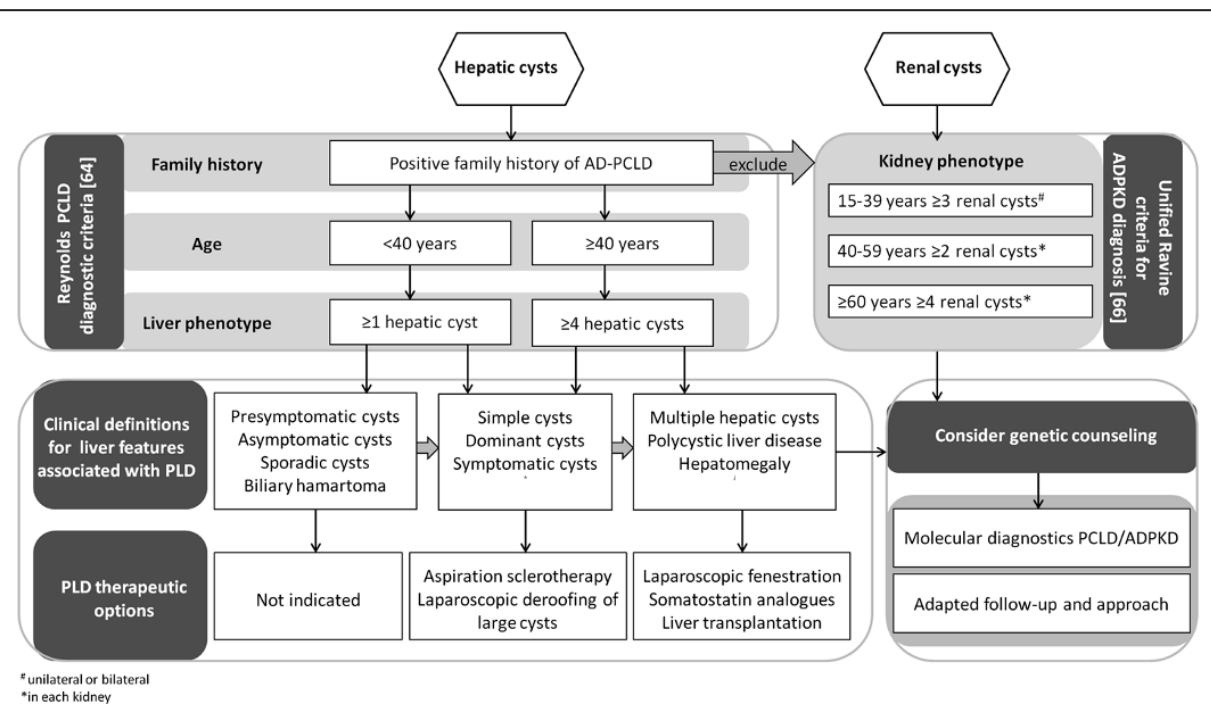

Figure 2 Comprehensive algorithm for diagnosis, management and genetic counseling in PCLD and ADPKD. The diagnostic criteria for PCLD and ADPKD compromises family history and age-related liver or kidney phenotype respectively $[64,66]$. PLD therapy is individually decided according to number, distribution and size of hepatic cysts [78]. Genetic counseling has an important role in symptomatic individuals with a positive family history for hepatic and/or renal cystogenesis in order to differentiate PLD and clinical management. 
ARPKD and other ciliopathies [8]. ARPKD has an incidence of 1/20,000 live births (ORPHA731; prevalence of $1.2 / 100,000)$ and a high peri-natal lethality. The predominant phenotype includes perinatal renal cysts and CHF [12]. Presence of cystic dilatation of intrahepatic biliary tree may be confused with disconnected hepatic cysts [17]. The gene product polyductin is located at the primary cilium suggesting molecular similarities with the ciliopathy ADPKD [8].

\section{Caroli disease and Caroli syndrome}

$\mathrm{CD}$ is characterized by saccular, cystic dilations of the more larger intrahepatic biliary system. In CS large and small intrahepatic bile duct ecstasies are accompanied with CHF. CS has been typically associated with renal disease as in ARPKD [7]. The incidence of CD is approximately $1 / 1,000,000$ births, but CS is more frequent (ORPHA53035; 250 cases). Both ARPKD and
CS have an autosomal recessive inheritance pattern [12].

\section{Genetic counseling in PCLD and ADPKD}

Both PCLD and ADPKD have an autosomal dominant inheritance pattern and the recurrence risk is $50 \%$. Genetic studies indicate an evident inter-familial clinical heterogeneity in PLD disease course among similar-aged patients. Secondly, intra-familial studies suggested a considerable phenotypic variability of hepatic cysts (Figure 3). Clinical asymptomatic or undiagnosed members contribute to underestimation of the actual disease prevalence $[24,41,61]$. It is estimated that the penetrance is $\sim 80 \%$ [63].

These considerations raise the question whether it is appropriate to screen members or children at-risk. Counseling should include discussion about insurance, employment and psychological factors. Genetic counseling is recommended in severely affected PLD and

A

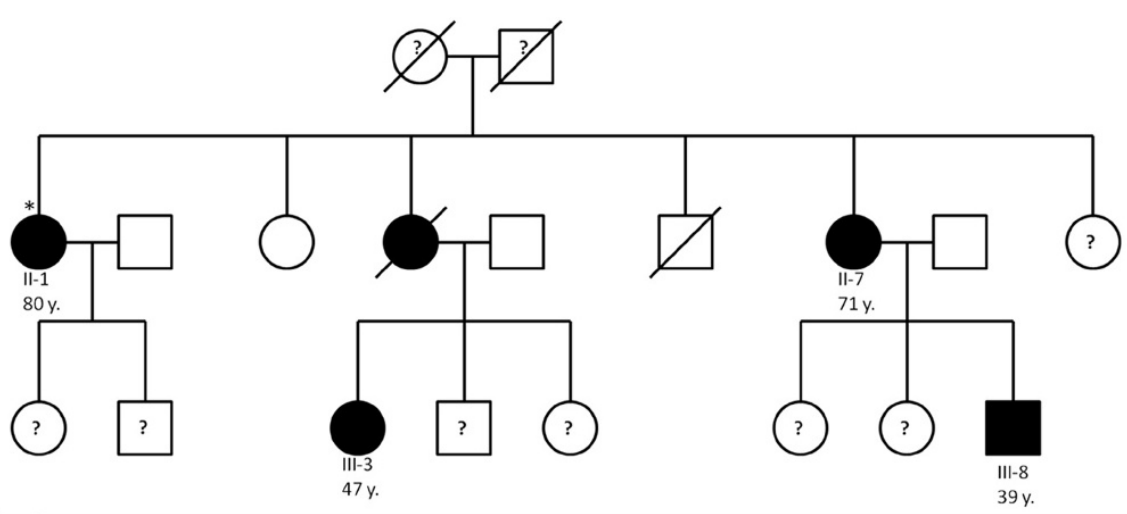

B

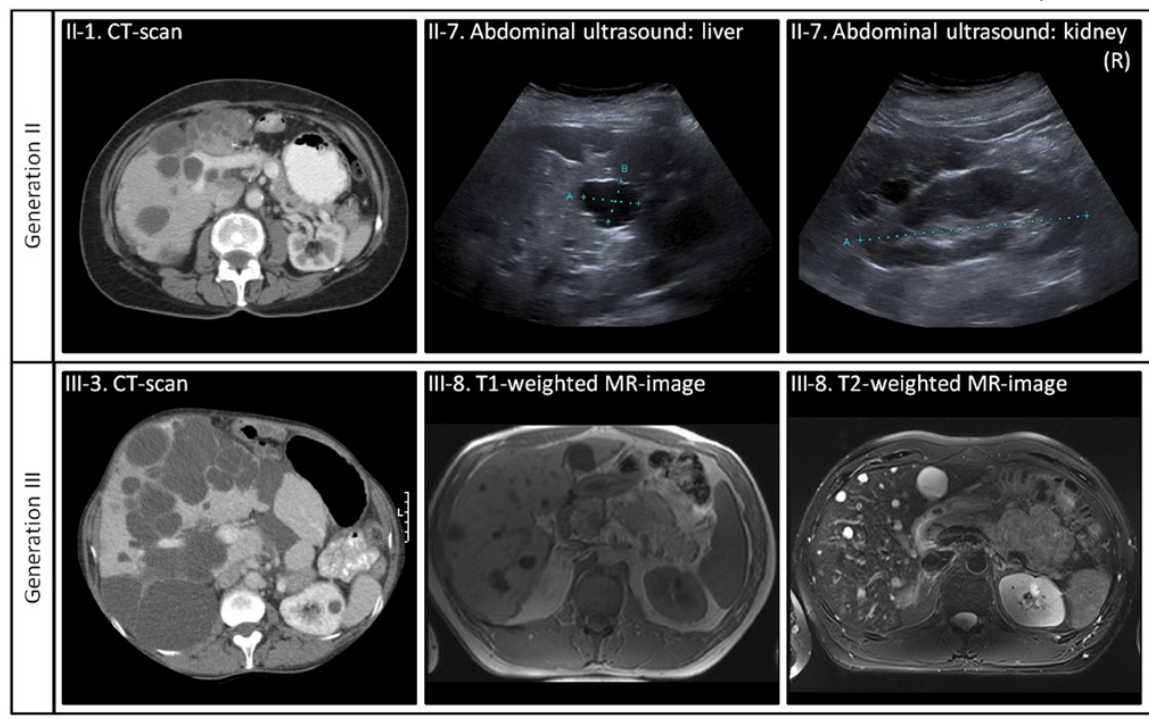

Figure 3 Intra-familial clinical heterogeneity in PCLD. Description of the data: (A) Pedigree of a PCLD family with PRKCSH gene mutation c.374_375delAG in affected individuals. The index patient $\left(^{*}\right)$ has 4 members with symptomatic PLD. Although the family history is positive, family members frequently are asymptomatic carriers or the liver phenotype remains unknown. (B) Axial CT-scanning, abdominal ultrasonography or MRI in 4 PCLD patients presented a variably number of hepatic cysts without renal disease. 
Table 2 Determinants and recommendations in severe PCLD and ADPKD

\section{Polycystic liver disease (PCLD)}

\begin{tabular}{|c|c|}
\hline Organ & Determinant \\
\hline \multirow[t]{5}{*}{ Liver } & Female sex \\
\hline & Aging $[21,22]$ \\
\hline & Environmental factors associated with PLD disease course [2 \\
\hline & $\begin{array}{l}\text {-Prolonged oral/exogenous female steroid use: estrogens, } \\
\text { contraceptive pill or (post-menopausal) hormonal replaceme } \\
\text { therapy }\end{array}$ \\
\hline & -Multiple pregnancies \\
\hline Brain & $\begin{array}{l}\text { Similar recommendations seem appropriate for patients with } \\
\text { isolated ADPLD, but more studies are required }[19,79]\end{array}$ \\
\hline Heart & Similar as in the general population [47] \\
\hline \multicolumn{2}{|c|}{ Autosomal dominant polycystic kidney disease (ADPKD) } \\
\hline Organ & Determinant \\
\hline \multirow[t]{9}{*}{ Kidney } & Environmental factors associated with renal cyst growth [83] \\
\hline & -caffeine \\
\hline & -smoking \\
\hline & Influencing factors for renal cystogenesis $[43,45]$ : \\
\hline & -hypertension ( $\leq 35$ years) - renal infection \\
\hline & -proteinuria - total kidney volume \\
\hline & -hematuria ( $<30$ years) - male sex \\
\hline & -urinary tract infection - low birth weight \\
\hline & -kidney stones - aging \\
\hline
\end{tabular}

PKD1 gene mutation have a more severe disease course and earlier onset of end-stage renal disease compared to PKD2 carriers [41]

Liver Female sex

Aging $[21,22]$

Environmental factors associated with PLD disease course [24,25]:

-prolonged oral/exogenous female steroid use: estrogens, contraceptive pill or (post-menopausal) hormonal replacement therapy

-multiple pregnancies

Renal function/glomular filtration rate [23]; in particular females [43]

Brain Patients at risk:

-positive family history of (ruptured) ICA or stroke $<50$ years old

-previously ruptured ICA

-warning symptoms: unusual headaches

-high-risk occupation (for example: airline pilot)

preparation for major elective surgery (for example: kidney transplantation) $[13,51]$

The position of the mutation in PKD1 is predictive for development of intracranial aneurysms [80]

Heart Screening is indicated $[13,45]$ :

-a murmur or systolic clicks are detected on examination
Recommendations

Stop exogenous estrogen use in female patients [78]

Advise alternative contraceptive strategies

Indiscriminate screening is not recommended at present [44]

No recommendations

\section{Recommendations}

Avoid (excessive) caffeine administration and nephrotoxic agents Smoking cessation

Hypertension $[43,45,46,81]$ :

-Routinely standardized blood pressure measurement

-Elektrocardiogram in hypertensive patients for LVH assessment

-Plasma LDL cholesterol control; urinary albumin excretion; left ventricular mass index calculation

-Angiotensin converting enzyme inhibitors and/or angiotensin receptor blockers

Dietary protein and salt restriction

Sufficient daily fluid intake

Molecular diagnostics [24]

Stop exogenous estrogen use in female patients [78]

Advise alternative contraceptive strategies

Patients with reasonable estimated life expectancy: periodic 3-5 years MR/CT-angiography screening [51]

Surveillance/rescreening after negative results in patients with a positive family history: $5-10$ years (high-to low-risk) [13,81]

Smoking cessation

Blood pressure control

Hyperlipidemia control [51]

Molecular diagnostics [80]

Echocardiography $[13,45]$ 
Table 2 Determinants and recommendations in severe PCLD and ADPKD (Continued)

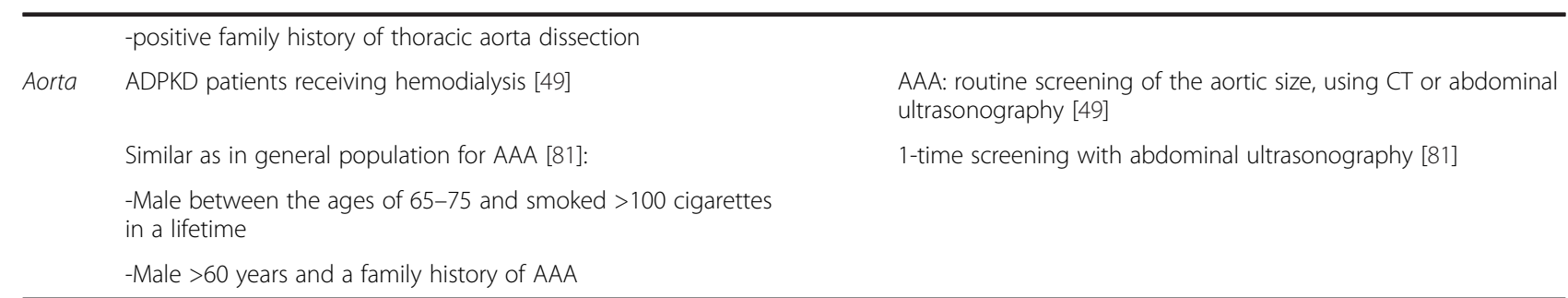

This scheme indicates distinct factors that are related to physical health and disease progression in PCLD and ADPKD patients. These clinical elements listed per organ may be valuable for consideration in management. Patients' mental condition and health-related quality of life should be assessed by standardized evaluation of symptoms in all PLD patients [82].

may afford differentiation between ADPKD and PCLD $[8,12]$.

Molecular diagnostics may assist the counseling process to establish a firm diagnosis in symptomatic patients and families. In particular ADPKD, determination of the responsible gene is useful for those who are at-risk in order to develop a strategy to prevent severe progressive disease events or complications [80]. If the family history for ICA is positive in an ADPKD family, screening of unaffected family members by MR-angiography is recommended [50,51,81]. Counseling or genetic testing is not advised in asymptomatic children [79].

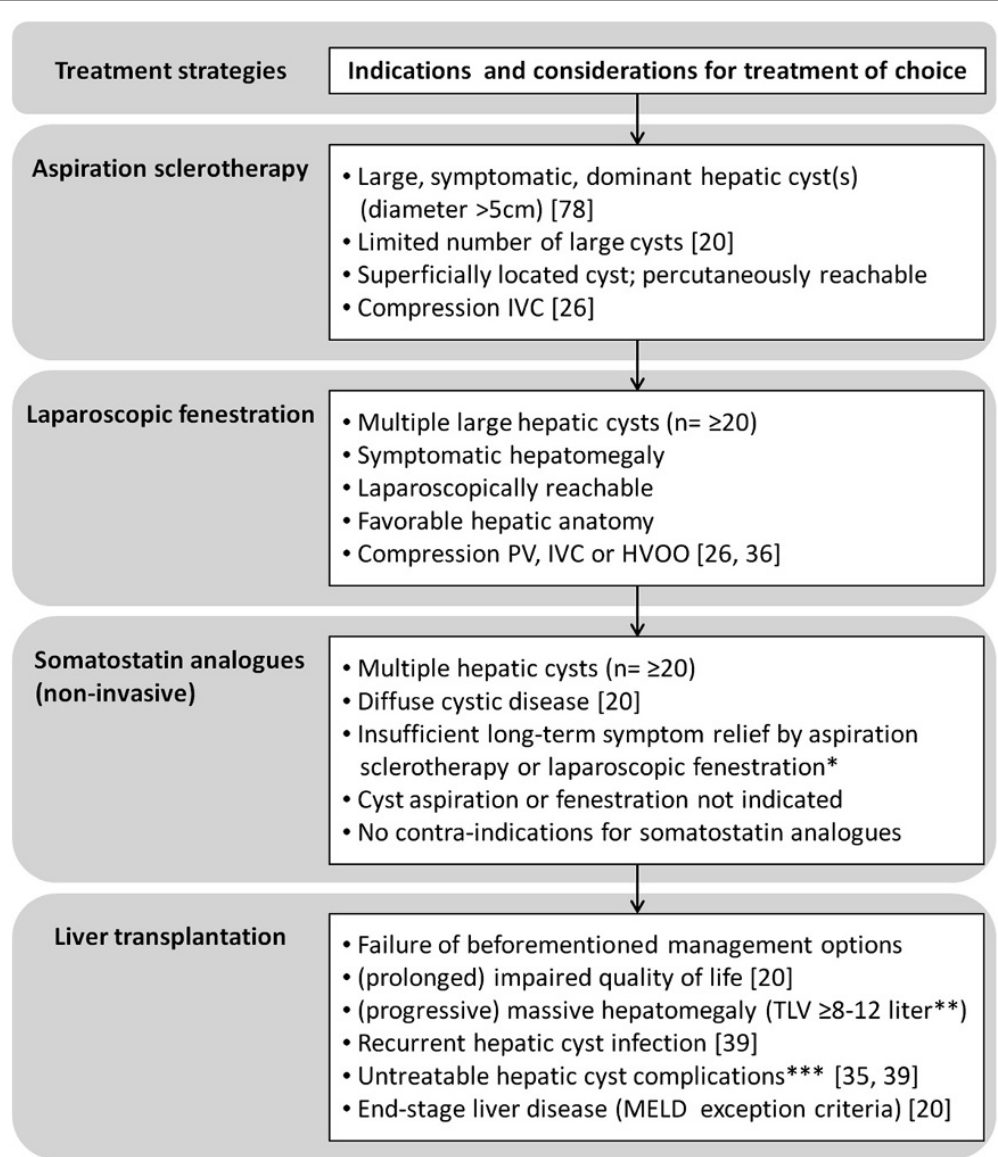

Figure 4 Indications and considerations for treatment strategies in symptomatic PLD. Schematic overview of relevant indications and considerations in PLD management. Patient characteristics and liver phenotype such as severity of clinical symptoms, age, (surgical) history, degree of hepatomegaly, and number, size and location of hepatic cysts are essential parameters for this decision. In general, the choice of procedure is an individual process in consultation with the patient. Severely affected individuals are patients with massive hepatomegaly, refractory symptoms, PLD-related complications and/or end-stage liver failure. Care and follow-up of these patients should be managed with caution. ${ }^{*}$ Notification: Results about treatment efficacy of prolonged or long-term somatostatin analogue use is unknown. ${ }^{*}$ Arbitrary total liver volume (TLV), because this outcome measurement is related to other parameters such as height, total body surface and sex. ${ }^{* * *}$ For example: recurrent hepatic cyst infection, HVOO. 


\section{Management and prognosis}

VMC is an asymptomatic condition without long-term consequences and treatment is not warranted. The primary aim of PLD therapy is to reduce symptoms by curtailing hepatic cyst development. The treatment of choice is driven by individual complaints [40]. Although the primary outcome measurement of PLD management is liver volume, assessment of symptoms associated with quality of life is an element for focus [82]. Therapeutic interventions are not warranted in asymptomatic patients.

The first advice in PCLD and ADPKD is to stop oral anticonceptives [20,78]. Although not formally investigated, the use other (non-systemic) contraceptives such as an intra-uterine device may be an acceptable alternative. Other guidelines are presented in Table $2[81,83]$. Supportive management with analgesics is the first-line treatment in patients with acute or chronic abdominal pain and tenderness.

The different invasive approaches with possible beneficial outcomes in independent studies include aspiration sclerotherapy, laparoscopic cyst deroofing or liver transplantation $[39,40,84]$. Current indications and considerations for invasive treatment are presented in Figure 4.

Treatment of portal hypertension and ascites are not different from that in patients with other causes. In a selected patient group were invasive procedures such as a vascular or bile duct stent placement optional for decompression of the portal vein, inferior vena cava or bile duct, or in HVOO treatment $[37,85]$. In general, management of vascular and bile duct complications due to hepatic cystogenesis consists of relieving the obstruction in order to improve venous and biliary drainage [26,35]. Although no concise guidelines are available, stents may give temporal symptom relief of portal hypertension, ascites and jaundice. A porto-systemic shunt may be indicated in presence of acute thrombosis or vascular compression to establish patent hepatic and portal venous flow, but should be weighed against possible complications. The primary aim is to ameliorate symptoms by cyst decompression in these advanced cases. This is often achieved by final treatment strategies including liver resection, hepatic fenestration procedures or liver transplantation [33].

Recent development of pharmacological options opened up new treatment strategies for severe PLD patients. Long-term follow-up studies with somatostatin analogues demonstrated that these agents consistently lower total liver volume in PLD patients [86,87]. A recent metaanalysis reported that somatostatin analogues is particularly effective in young females [88].

\section{Conclusion}

PLD compromises a clinically heterogeneous liver phenotype identified in VMC, ADPKD and PCLD patients. Massively enlarged livers are present in a subset of ADPKD and PCLD. Genetics and environmental factors such as exogenous estrogen intake and number of pregnancies contribute to disease progression. A considerable intra-familial variability in liver phenotype and extrahepatic features makes screening modalities uncertain in PCLD. Evaluation of PLD-related symptoms and quality of life are necessary to decide beneficial management.

\section{URL}

Human Gene Mutation Database for Human Genetics Research; HGMD ${ }^{\circ}$ Professional $2013.3-27^{\text {th }}$ September 2013; http://www.biobase-international.com/product/hgmd.

\begin{abstract}
Abbreviations
AAA: Abdominal aorta aneurysm; ADPKD: Autosomal dominant polycystic kidney disease; ARPKD: Autosomal recessive polycystic kidney disease; CD: Caroli disease; CS: Caroli syndrome; CT: Computer tomography; CHF: congenital hepatic fibrosis; DPM: Ductal plate malformation; ER: Endoplasmic reticulum; HVOO: Hepatic venous outflow obstruction; ICA: Intracranial aneurysm; IVC: Inferior vena cava; LVH: Left ventricle hypertrophy; MELD: Model for end-stage liver disease; MRI: Magnetic resonance imaging; PC1: PC2 polycystin-1, -2; PCLD: Isolated polycystic liver disease (autosomal dominant); PKD1: PKD2 polycystic kidney disease-1, -2; PLD: Polycystic liver disease; PRKCSH: Protein kinase C substrate $80 \mathrm{~K}-\mathrm{H}$ (80-kDa protein, heavy chain); SEC63: Saccharomyces cerevisiae homolog 63; VMC: Von Meyenburg complexes.
\end{abstract}

\section{Competing interests}

Authors declare that they have no competing interests.

\section{Authors' contributions}

WC researched the data and drafted the manuscript. WC and JD contributed to the content and wrote the article. JD is responsible for critical revision of the content. Both authors read and approved the final manuscript.

\section{Acknowledgements}

We acknowledge the support of the Institute for Genetic and Metabolic Disease of the Radboud university medical center, The Netherlands. The authors thank M.K. Neijenhuis MD, T.F. Wijnands MD and T.J.G. Gevers MD from the Department of Gastroenterology and Hepatology, Radboud university medical center, for proofreading the article.

Received: 8 January 2014 Accepted: 17 April 2014 Published: 1 May 2014

\section{References}

1. Roskams T, Desmet V: Embryology of extra- and intrahepatic bile ducts, the ductal plate. Anat Rec (Hoboken) 2008, 291:628-635.

2. Raynaud P, Carpentier R, Antoniou A, Lemaigre FP: Biliary differentiation and bile duct morphogenesis in development and disease. Int J Biochem Cell Biol 2011, 43:245-256.

3. Strazzabosco M, Fabris L: Development of the bile ducts: essentials for the clinical hepatologist. J Hepatol 2012, 56:1159-1170.

4. Drenth JP, Chrispijn M, Bergmann C: Congenital fibrocystic liver diseases. Best Pract Res Clin Gastroenterol 2010, 24:573-584.

5. Zheng $R Q$, Zhang $B$, Kudo $M$, Onda $H$, Inoue $T$ : Imaging findings of biliary hamartomas. World J Gastroenterol 2005, 11:6354-6359.

6. Raynaud P, Tate J, Callens C, Cordi S, Vandersmissen P, Carpentier R, Sempoux C, Devuyst O, Pierreux CE, Courtoy P, Dahan K, Delbecque K, Lepreux S, Pontoglio M, Guay-Woodford LM, Lemaigre FP: A classification of ductal plate malformations based on distinct pathogenic mechanisms of biliary dysmorphogenesis. Hepatology 2011, 53:1959-1966.

7. Desmet VJ: Ludwig symposium on biliary disorders-part I. Pathogenesis of ductal plate abnormalities. Mayo Clin Proc 1998, 73:80-89.

8. Hildebrandt F, Benzing T, Katsanis N: Ciliopathies. N Engl J Med 2011, 364:1533-1543.

9. Mortele KJ, Ros PR: Cystic focal liver lesions in the adult: differential CT and MR imaging features. Radiographics 2001, 21:895-910. 
10. Salo J, Bru C, Vilella A, Gines P, Gilabert R, Castells A, Bruguera M, Rodes J: Bile-duct hamartomas presenting as multiple focal lesions on hepatic ultrasonography. Am J Gastroenterol 1992, 87:221-223.

11. Lemaigre FP: Mechanisms of liver development: concepts for understanding liver disorders and design of novel therapies. Gastroenterology 2009, 137:62-79.

12. Gunay-Aygun M: Liver and kidney disease in ciliopathies. Am J Med Genet C: Semin Med Genet 2009, 151C:296-306.

13. Torres VE, Harris PC, Pirson Y: Autosomal dominant polycystic kidney disease. Lancet 2007, 369:1287-1301.

14. Bae KT, Zhu F, Chapman AB, Torres VE, Grantham JJ, Guay-Woodford LM, Baumgarten DA, King BF Jr, Wetzel LH, Kenney PJ, Brummer ME, Bennett WM, Klahr S, Meyers CM, Zhang X, Thompson PA, Miller JP, Consortium for Radiologic Imaging Studies of Polycystic Kidney Disease (CRISP): Magnetic resonance imaging evaluation of hepatic cysts in early autosomal-dominant polycystic kidney disease: the Consortium for Radiologic Imaging Studies of Polycystic Kidney Disease cohort. Clin J Am Soc Nephrol 2006, 1:64-69.

15. Van Keimpema L, De Koning DB, Van Hoek B, Van Den Berg AP, Van Oijen MG, De Man RA, Nevens F, Drenth JP: Patients with isolated polycystic liver disease referred to liver centres: clinical characterization of 137 cases. Liver Int 2011, 31:92-98.

16. Redston MS, Wanless IR: The hepatic von Meyenburg complex: prevalence and association with hepatic and renal cysts among 2843 autopsies [corrected]. Mod Pathol 1996, 9:233-237.

17. Brancatelli G, Federle MP, Vilgrain V, Vullierme MP, Marin D, Lagalla R: Fibropolycystic liver disease: CT and MR imaging findings. Radiographics 2005, 25(3):659-670

18. Karahan Ol, Kahriman G, Soyuer I, Ok E: Hepatic von Meyenburg complex simulating biliary cystadenocarcinoma. Clin Imaging 2007, 31:50-53.

19. Qian Q, Li A, King BF, Kamath PS, Lager DJ, Huston J 3rd, Shub C, Davila S, Somlo S, Torres VE: Clinical profile of autosomal dominant polycystic liver disease. Hepatology 2003, 37:164-171.

20. Temmerman F, Missiaen L, Bammens B, Laleman W, Cassiman D, Verslype C, Van Pelt J, Nevens F: Systematic review: the pathophysiology and management of polycystic liver disease. Aliment Pharmacol Ther 2011, 34:702-713.

21. Chapman AB: Cystic disease in women: clinical characteristics and medical management. Adv Ren Replace Ther 2003, 10:24-30.

22. Sherstha R, McKinley C, Russ P, Scherzinger A, Bronner T, Showalter R, Everson GT: Postmenopausal estrogen therapy selectively stimulates hepatic enlargement in women with autosomal dominant polycystic kidney disease. Hepatology 1997, 26:1282-1286.

23. Gabow PA, Johnson AM, Kaehny WD, Manco-Johnson ML, Duley IT, Everson GT: Risk factors for the development of hepatic cysts in autosomal dominant polycystic kidney disease. Hepatology 1990, 11:1033-1037.

24. Pei Y: Diagnostic approach in autosomal dominant polycystic kidney disease. Clin J Am Soc Nephrol 2006, 1:1108-1114.

25. Peters DJ, Breuning MH: Autosomal dominant polycystic kidney disease: modification of disease progression. Lancet 2001, 358:1439-1444.

26. Macutkiewicz C, Plastow R, Chrispijn M, Filobbos R, Ammori BA, Sherlock DJ, Drenth JP, O'Reilly DA: Complications arising in simple and polycystic liver cysts. World J Hepatol 2012, 4:406-411.

27. Hoevenaren IA, Wester R, Schrier RW, McFann K, Doctor RB, Drenth JP, Everson GT: Polycystic liver: clinical characteristics of patients with isolated polycystic liver disease compared with patients with polycystic liver and autosomal dominant polycystic kidney disease. Liver Int 2008, 28:264-270.

28. Marion Y, Brevartt C, Plard L, Chiche L: Hemorrhagic liver cyst rupture: an unusual life-threatening complication of hepatic cyst and literature review. Ann Hepatol 2013, 12:336-339.

29. Jouret F, Lhommel R, Devuyst O, Annet L, Pirson Y, Hassoun Z, Kanaan N: Diagnosis of cyst infection in patients with autosomal dominant polycystic kidney disease: attributes and limitations of the current modalities. Nephrol Dial Transplant 2012, 27:3746-3751.

30. Waanders E, Van Keimpema L, Brouwer JT, Van Oijen MG, Aerts R, Sweep FC, Nevens F, Drenth JP: Carbohydrate antigen 19-9 is extremely elevated in polycystic liver disease. Liver Int 2009, 29:1389-1395.

31. Kanaan N, Goffin E, Pirson Y, Devuyst O, Hassoun Z: Carbohydrate antigen 19-9 as a diagnostic marker for hepatic cyst infection in autosomal dominant polycystic kidney disease. Am J Kidney Dis 2010, 55:916-922.

32. Akriviadis EA, Steindel $H$, Ralls $P$, Redeker AG: Spontaneous rupture of nonparasitic cyst of the liver. Gastroenterology 1989, 97:213-215.
33. Uddin W, Ramage JK, Portmann B, Wilson P, Benjamin I, Tan KC, Williams R: Hepatic venous outflow obstruction in patients with polycystic liver disease: pathogenesis and treatment. Gut 1995, 36:142-145.

34. Johnstone AJ, Turnbull LW, Allan PL, Garden OJ: Cholangitis and Budd Chiari syndrome as complications of simple cystic liver disease. HPB Surg 1993, 6:223-227. discussion 227-228.

35. Torres VE, Rastogi S, King BF, Stanson AW, Gross JB Jr, Nogorney DM: Hepatic venous outflow obstruction in autosomal dominant polycystic kidney disease. J Am Soc Nephrol 1994, 5:1186-1192.

36. Grams J, Teh SH, Torres VE, Andrews JC, Nagorney DM: Inferior vena cava stenting: a safe and effective treatment for intractable ascites in patients with polycystic liver disease. J Gastrointest Surg 2007, 11:985-990.

37. Chauveau D, Grunfeld JP, Durand F, Belghiti J: Ascites in a polycystic patient. Nephrol Dial Transplant 1997, 12:228-230.

38. Lai EC, Wong J: Symptomatic nonparasitic cysts of the liver. World J Surg 1990, 14:452-456.

39. Van Keimpema L, Nevens F, Adam R, Porte RJ, Fikatas P, Becker T, Kirkegaard P, Metselaar HJ, Drenth JP, European L: Intestine Transplant A: Excellent survival after liver transplantation for isolated polycystic liver disease: an European Liver Transplant Registry study. Transpl Int 2011, 24:1239-1245.

40. Morgan DE, Lockhart ME, Canon CL, Holcombe MP, Bynon JS: Polycystic liver disease: multimodality imaging for complications and transplant evaluation. Radiographics 2006, 26:1655-1668. quiz 1655.

41. Hateboer N, Dijk MA V, Bogdanova N, Coto E, Saggar-Malik AK, San Millan $J$, Torra R, Breuning M, Ravine D: Comparison of phenotypes of polycystic kidney disease types 1 and 2. European PKD1-PKD2 Study Group. Lancet 1999, 353:103-107.

42. Chapman AB, Stepniakowski K, Rahbari-Oskoui F: Hypertension in autosomal dominant polycystic kidney disease. Adv Chronic Kidney Dis 2010, 17:153-163.

43. Torres VE, Chapman AB, Perrone RD, Bae KT, Abebe KZ, Bost JE, Miskulin DC, Steinman TI, Braun WE, Winklhofer FT, Hogan MC, Oskoui FR, Kelleher C, Masoumi A, Glockner J, Halin NJ, Martin DR, Remer E, Patel N, Pedrosa I, Wetzel LH, Thompson PA, Miller JP, Meyers CM, Schrier RW, HALT PKD Study Group: Analysis of baseline parameters in the HALT polycystic kidney disease trials. Kidney Int 2012, 81:577-585.

44. Qian Q: Isolated polycystic liver disease. Adv Chronic Kidney Dis 2010, 17:181-189.

45. Ecder T, Schrier RW: Cardiovascular abnormalities in autosomal-dominant polycystic kidney disease. Nat Rev Nephrol 2009, 5:221-228.

46. De Almeida EA, De Oliveira El, Lopes JA, Almeida AG, Lopes MG, Prata MM: Diastolic function in several stages of chronic kidney disease in patients with autosomal dominant polycystic kidney disease: a tissue Doppler imaging study. Kidney Blood Press Res 2007, 30:234-239.

47. Gevers TJ, De Koning DB, Van Dijk AP, Drenth JP: Low prevalence of cardiac valve abnormalities in patients with autosomal dominant polycystic liver disease. Liver Int 2012, 32:690-692.

48. Timio M, Monarca C, Pede S, Gentili S, Verdura C, Lolli S: The spectrum of cardiovascular abnormalities in autosomal dominant polycystic kidney disease: a 10-year follow-up in a five-generation kindred. Clin Nephrol 1992, 37:245-251.

49. Kato A, Takita T, Furuhashi M, Maruyama Y, Hishida A: Abdominal aortic aneurysms in hemodialysis patients with autosomal dominant polycystic kidney disease. Nephron 2001, 88:185-186.

50. Schievink WI, Spetzler RF: Screening for intracranial aneurysms in patients with isolated polycystic liver disease. J Neurosurg 1998, 89:719-721.

51. Pirson Y, Chauveau D, Torres V: Management of cerebral aneurysms in autosomal dominant polycystic kidney disease. J Am Soc Nephrol 2002, 13:269-276.

52. Torra R, Nicolau C, Badenas C, Navarro S, Perez L, Estivill X, Darnell A: Ultrasonographic study of pancreatic cysts in autosomal dominant polycystic kidney disease. Clin Nephrol 1997, 47:19-22

53. Torra R, Sarquella J, Calabia J, Marti J, Ars E, Fernandez-Llama P, Ballarin J: Prevalence of cysts in seminal tract and abnormal semen parameters in patients with autosomal dominant polycystic kidney disease. Clin J Am Soc Nephrol 2008, 3:790-793.

54. Morris-Stiff G, Coles G, Moore R, Jurewicz A, Lord R: Abdominal wall hernia in autosomal dominant polycystic kidney disease. Br J Surg 1997, 84:615-617.

55. Sharp CK, Zeligman BE, Johnson AM, Duley I, Gabow PA: Evaluation of colonic diverticular disease in autosomal dominant polycystic kidney disease without end-stage renal disease. Am J Kidney Dis 1999, 34:863-868. 
56. Drenth JP, Te Morsche RH, Smink R, Bonifacino JS, Jansen JB: Germline mutations in PRKCSH are associated with autosomal dominant polycystic liver disease. Nat Genet 2003, 33:345-347

57. Li A, Davila S, Furu L, Qian Q, Tian X, Kamath PS, King BF, Torres VE, Somlo $S$ : Mutations in PRKCSH cause isolated autosomal dominant polycystic liver disease. Am J Hum Genet 2003, 72:691-703.

58. Davila S, Furu L, Gharavi AG, Tian X, Onoe T, Qian Q, Li A, Cai Y, Kamath PS, King BF, Azurmendi PJ, Tahvanainen P, Kääriäinen H, Höckerstedt K, Devuyst O, Pirson Y, Martin RS, Lifton RP, Tahvanainen E, Torres VE, Somlo S: Mutations in SEC63 cause autosomal dominant polycystic liver disease. Nat Genet 2004, 36:575-577.

59. Drenth JP, Martina JA, van de Kerkhof R, Bonifacino JS, Jansen JB: Polycystic liver disease is a disorder of cotranslational protein processing. Trends Mol Med 2005, 11:37-42.

60. Janssen MJ, Waanders E, Woudenberg J, Lefeber DJ, Drenth JP: Congenital disorders of glycosylation in hepatology: the example of polycystic liver disease. J Hepatol 2010, 52:432-440.

61. Waanders E, Te Morsche RH, De Man RA, Jansen JB, Drenth JP: Extensive mutational analysis of PRKCSH and SEC63 broadens the spectrum of polycystic liver disease. Hum Mutat 2006, 27:830.

62. Rossetti S, Consugar MB, Chapman AB, Torres VE, Guay-Woodford LM Grantham JJ, Bennett WM, Meyers CM, Walker DL, Bae K, Zhang QJ, Thompson PA, Miller JP, Harris PC, CRISP Consortium: Comprehensive molecular diagnostics in autosomal dominant polycystic kidney disease. J Am Soc Nephrol 2007, 18:2143-2160.

63. Waanders E, Venselaar H, Te Morsche RH, De Koning DB, Kamath PS, Torres VE, Somlo S, Drenth JP: Secondary and tertiary structure modeling reveals effects of novel mutations in polycystic liver disease genes PRKCSH and SEC63. Clin Genet 2010, 78:47-56.

64. Reynolds DM, Falk CT, Li A, King BF, Kamath PS, Huston J 3rd, Shub C, Iglesias DM, Martin RS, Pirson Y, Torres VE, Somlo S: Identification of a locus for autosomal dominant polycystic liver disease, on chromosome 19p13.2-13.1. Am J Hum Genet 2000, 67:1598-1604.

65. Ravine D, Gibson RN, Walker RG, Sheffield LJ, Kincaid-Smith P, Danks DM: Evaluation of ultrasonographic diagnostic criteria for autosomal dominant polycystic kidney disease 1. Lancet 1994, 343:824-827.

66. Pei $Y$, Obaji J, Dupuis A, Paterson AD, Magistroni R, Dicks E, Parfrey P Cramer B, Coto E, Torra R, San Millan JL, Gibson R, Breuning M, Peters D, Ravine D: Unified criteria for ultrasonographic diagnosis of ADPKD. J Am Soc Nephrol 2009, 20:205-212.

67. Ariza M, Alvarez V, Marin R, Aguado S, Lopez-Larrea C, Alvarez J, Menendez MJ, Coto E: A family with a milder form of adult dominant polycystic kidney disease not linked to the PKD1 (16p) or PKD2 (4q) genes. J Med Genet 1997, 34:587-589.

68. Paterson AD, Pei Y: Is there a third gene for autosomal dominant polycystic kidney disease? Kidney Int 1998, 54:1759-1761.

69. Daoust MC, Reynolds DM, Bichet DG, Somlo S: Evidence for a third genetic locus for autosomal dominant polycystic kidney disease. Genomics 1995, 25:733-736.

70. Watnick TJ, Torres VE, Gandolph MA, Qian F, Onuchic LF, Klinger KW, Landes G, Germino GG: Somatic mutation in individual liver cysts supports a two-hit model of cystogenesis in autosomal dominant polycystic kidney disease. Mol Cell 1998, 2:247-251.

71. Pei Y, Watnick T, He N, Wang K, Liang Y, Parfrey P, Germino G, St George-Hyslop P: Somatic PKD2 mutations in individual kidney and liver cysts support a "two-hit" model of cystogenesis in type 2 autosomal dominant polycystic kidney disease. J Am Soc Nephrol 1999, 10:1524-1529.

72. Janssen MJ, Waanders E, Te Morsche RH, Xing R, Dijkman HB, Woudenberg J, Drenth JP: Secondary, somatic mutations might promote cyst formation in patients with autosomal dominant polycystic liver disease. Gastroenterology 2011, 141:2056-2063 e2052

73. Janssen MJ, Salomon J, Te Morsche RH, Drenth JP: Loss of heterozygosity is present in SEC63 germline carriers with polycystic liver disease. PLOS ONE 2012, 7:e50324.

74. Bergmann C, Von Bothmer J, Ortiz Bruchle N, Venghaus A, Frank V Fehrenbach H, Hampel T, Pape L, Buske A, Jonsson J, Sarioglu N, Santos A, Ferreira JC, Becker JU, Cremer R, Hoefele J, Benz MR, Weber LT, Buettner R, Zerres K: Mutations in multiple PKD genes may explain early and severe polycystic kidney disease. J Am Soc Nephrol 2011, 22:2047-2056.

75. Nichols MT, Gidey E, Matzakos T, Dahl R, Stiegmann G, Shah RJ, Grantham JJ, Fitz JG, Doctor RB: Secretion of cytokines and growth factors into autosomal dominant polycystic kidney disease liver cyst fluid. Hepatology 2004, 40:836-846.

76. Waanders E, Lameris AL, Op den Camp HJ, Pluk W, Gloerich J, Strijk SP Drenth JP: Hepatocystin is not secreted in cyst fluid of hepatocystin mutant polycystic liver patients. J Proteome Res 2008, 7:2490-2495.

77. Alvaro D, Onori P, Alpini G, Franchitto A, Jefferson DM, Torrice A, Cardinale V, Stefanelli F, Mancino MG, Strazzabosco M, Angelico M, Attili A, Gaudio E: Morphological and functional features of hepatic cyst epithelium in autosomal dominant polycystic kidney disease. Am J Pathol 2008, 172:321-332.

78. Gevers TJ, Drenth JP: Diagnosis and management of polycystic liver disease. Nat Rev Gastroenterol Hepatol 2013, 10:101-108.

79. Tahvanainen $\mathrm{E}$, Tahvanainen $\mathrm{P}$, Kaariainen $\mathrm{H}$, Hockerstedt $\mathrm{K}$ : Polycystic liver and kidney diseases. Ann Med 2005, 37:546-555.

80. Rossetti S, Chauveau D, Kubly V, Slezak JM, Saggar-Malik AK, Pei Y, Ong AC, Stewart F, Watson ML, Bergstralh EJ, Winearls CG, Torres VE, Harris PC: Association of mutation position in polycystic kidney disease 1 (PKD1) gene and development of a vascular phenotype. Lancet 2003, 361:2196-2201

81. Luciano RL, Dahl NK: Extra-renal manifestations of ADPKD: considerations for routine screening and management. Nephrol Dial Transplant 2014, 29:247-254.

82. Wijnands TF, Neijenhuis MK, Kievit W, Nevens F, Hogan MC, Torres VE, Gevers TJ, Drenth JP: Evaluating health-related quality of life in patients with polycystic liver disease and determining the impact of symptoms and liver volume. Liver Int 2013. doi:10.1111/liv.12430.

83. Belibi FA, Wallace DP, Yamaguchi T, Christensen M, Reif G, Grantham JJ: The effect of caffeine on renal epithelial cells from patients with autosomal dominant polycystic kidney disease. J Am Soc Nephrol 2002, 13:2723-2729.

84. Drenth JP, Chrispijn M, Nagorney DM, Kamath PS, Torres VE: Medical and surgical treatment options for polycystic liver disease. Hepatology 2010, 52:2223-2230

85. Mudge DW, Taylor J, Bannister KM: Hepatic vein stenting for recurrent ascites in polycystic liver and kidney disease. Nephrol Dial Transplant 2005, 20:2566-2568.

86. Chrispijn M, Nevens F, Gevers TJ, Vanslembrouck R, Van Oijen MG, Coudyzer W, Hoffmann AL, Dekker HM, De Man RA, Van Keimpema L, Drenth JP: The long-term outcome of patients with polycystic liver disease treated with lanreotide. Aliment Pharmacol Ther 2012, 35:266-274.

87. Hogan MC, Masyuk TV, Page L, Holmes DR 3rd, Li X, Bergstralh EJ, Irazabal MV, Kim B, King BF, Glockner JF, Larusso NF, Torres VE: Somatostatin analog therapy for severe polycystic liver disease: results after 2 years. Nephrol Dial Transplant 2012, 27:3532-3539.

88. Gevers TJ, Inthout J, Caroli A, Ruggenenti P, Hogan MC, Torres VE, Nevens F, Drenth JP: Young women with polycystic liver disease respond best to somatostatin analogues: a pooled analysis of individual patient data. Gastroenterology 2013, 145:357-365. e351-352.

\section{doi:10.1186/1750-1172-9-69}

Cite this article as: Cnossen and Drenth: Polycystic liver disease: an overview of pathogenesis, clinical manifestations and management. Orphanet Journal of Rare Diseases 2014 9:69.

\section{Submit your next manuscript to BioMed Central and take full advantage of:}

- Convenient online submission

- Thorough peer review

- No space constraints or color figure charges

- Immediate publication on acceptance

- Inclusion in PubMed, CAS, Scopus and Google Scholar

- Research which is freely available for redistribution 